\title{
Whole Exome Sequencing Reveals a Mutation in CRYBB2 in a Large Mexican Family with Autosomal Dominant Pulverulent Cataract
}

\author{
Olga Messina-Baas ${ }^{a}$ Manuel L. Gonzalez-Garay d Luz M. González-Huertab \\ Jaime Toral-López ${ }^{c}$ Sergio A. Cuevas-Covarrubias ${ }^{c}$ \\ Departments of a Ophthalmology and ${ }^{b}$ Medical Genetics, Hospital General de México, Facultad de Medicina, \\ UNAM, Mexico City, and ' Department of Medical Genetics, Centro Medico, ISSEMyM, Ecatepec de Morelos, Mexico; \\ ${ }^{\mathrm{d}}$ Division of Next Generation Sequencing, Center for Molecular Imaging, The Brown Foundation Institute of \\ Molecular Medicine, University of Texas, Houston, Tex., USA
}

\section{Key Words}

Autosomal dominant pulverulent cataract · Clinical heterogeneity - CRYBB2 - CRYBB2P1 - Whole exome sequencing

\begin{abstract}
Congenital cataract, an important cause of reversible blindness, is due to several causes including Mendelian inheritance. Thirty percent of cataracts are hereditary with participation of the gamma crystallin genes. Clinical and genetic heterogeneity is observed in patients with gene mutations and congenital cataract; about 40 genetic loci have been associated with hereditary cataract. In this study, we identified the underlying genetic cause of an autosomal dominant pulverulent cataract (ADPC) in a large Mexican family. Twentyone affected patients and 20 healthy members of a family with ADPC were included. Genomic DNA was analyzed by whole exome sequencing in the proband, a normal daughter, and in an affected son, whereas DNA Sanger sequencing was performed in all members of the family. After the bioinformatics analysis, all samples were genotyped using Sanger sequencing to eliminate variants that do not cosegregate with the cataract. We observed a perfect cosegregation of a nonsense mutation c.475C>T (p.Q155*) in exon 6 of the $C R Y B B 2$ gene with ADPC. We calculated a logarithm of the
\end{abstract}

odds score of 5.5. This mutation was not detected in healthy members of the family and in 100 normal controls. This is the first Mexican family with ADPC associated with a p.Q155* mutation. Interestingly, this specific mutation in the CRYBB2 gene seems to be exclusively associated with pulverulent/ cerulean cataract (with some clinical variability) independent of the population's genetic background.

(c) 2016 S. Karger AG, Basel

A cataract is any opacity of the crystalline lens. There are many causes for cataracts, but they are normally associated with the breakdown of the lens architecture. It is generally thought that mutations in the crystalline or other lens proteins cause protein aggregation and, consequently, opacity of the crystalline lens [Shiels and Hejtmancik, 2007]. Three major crystalline lens components are $\alpha$-, $\beta$-, and $\gamma$-crystallins. $\beta$-crystallin is subdivided into acidic $(\beta \mathrm{A} 1, \beta \mathrm{A} 2, \beta \mathrm{A} 3$, and $\beta \mathrm{A} 4)$ and basic $(\beta \mathrm{B} 1, \beta \mathrm{B} 2$, and $\beta B 3)$ proteins. $\beta$-Crystallins form heterogeneous oligomers in the lens [Liu and Liang, 2005]. Hereditary congenital cataracts (HCCs) tend to be inherited in a Mendelian fashion, but they are clinically and genetically heterogeneous with high penetrance [Shafie et al., 2006; Bateman et al., 2007]. HCCs represent $10 \%$ of the treatable causes of childhood blindness [Lund et al., 1992; Gilbert et al.,

\section{KARGER}

E-Mail karger@karger.com

www.karger.com/msy
(C) 2016 S. Karger AG, Basel

$1661-8769 / 16 / 0072-0087 \$ 39.50 / 0$
Dr. Sergio A. Cuevas-Covarrubias

Departamento de Genética Médica, Hospital General de México

Dr. Balmis 148 Col. Doctores

Mexico City 06726 (Mexico)

E-Mail sergioa@ servidor.unam.mx 
Fig. 1. Pedigree of the family showing affected patients with autosomal dominant pulverulent cataract (black symbols) and unaffected subjects (open symbols). The arrow indicates the proband. A diagonal line indicates that the person is deceased. Numbers indicate the age at diagnosis or at surgery.

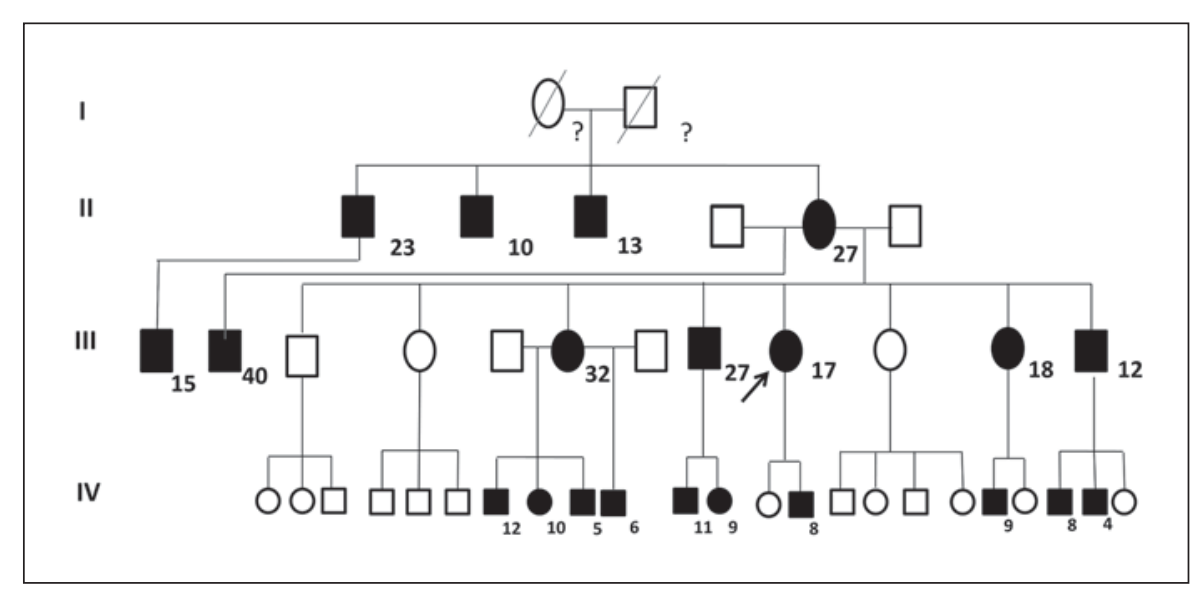

1993]. In developed countries, the prevalence of HCCs ranges from 0.63 to 13.6 per 10,000 births [Stoll et al., 1992; Bermejo and Martinez-Frias, 1998; Muñoz and West, 2002; Bhatti et al., 2003]. Thirty percent of cataracts are hereditary with a predominance of the nonsyndromic autosomal dominant forms [Rahi and Dezateux, 2000]. Currently, there are over 40 genetic loci which have been associated with HCCs [Hejtmancik, 2008]. Mutations in the CRYBB2 gene (OMIM 123620) have been associated with HCCs. Presently, there are 12 missense mutations [Santhiya et al., 2004, 2010; Pauli et al., 2007; Lou et al., 2009; Mothobi et al., 2009; Wang et al., 2011; Yao et al., 2011; Weisschuh et al., 2012; Chen et al., 2013; Faletra et al., 2013; Gillespie et al., 2014; Sun et al., 2014] and 2 nonsense mutations, p.Q155* [Litt et al., 1997; Gill et al., 2000; Vanita et al., 2001; Yao et al., 2005; Bateman et al., 2007; Devi et al., 2008; Li et al., 2008; Wang et al., 2009] and p.Y159* [Hansen et al., 2009] (table 1). Both types of mutation present clinical variability [Shiels et al., 2010]. The $C R Y B B 2$ gene belongs to the $\beta$-crystallin family together with 7 other genes (4CRYBA and $3 C R Y B B$ ) in different chromosomes. Four $\beta$-crystallin genes (CRYBB1, BB2, $B B 3$, and $B A 4$ ) are expressed in the eye. There is one pseudogene (CRYBB2P1) that is transcribed in several tissues, except in the eye, but there are no proteins associated with this pseudogene (UCSC Genome Bioinformatics Group). The CRYBB2 gene encompasses 6 exons with the start of the translation in the second exon. This exon encodes the $\mathrm{NH}-2$ terminal site and the other 4 exons encode one Greek key motif each [Inana et al., 1983]. The N- and Cterminal regions of the $\beta$-crystallin [Lubsen et al., 1988] are postulated to be essential for the maintenance of lens transparency [Bax et al., 1990; Norledge et al., 1997]. The $C R Y B B 2$ gene has $97 \%$ whole homology with the pseudogene CRYBB2P1 and 95\% homology with exon 6 . Whole exome sequencing (WES) has been successfully applied for molecular characterization of heterogeneous conditions and in the identification of novel genes [Bamshad et al., 2011; Goh and Choi, 2012]. Since the specific cataract phenotype is typically not sufficient to predict which gene is mutated in a family [Hejtmancik, 2008], WES represents an efficient method of screening to identify affected genes in congenital cataracts. In the present study, we analyzed an extensive Mexican pedigree in a family affected by autosomal dominant pulverulent cataract (ADPC).

\section{Material and Methods}

Patients

Twenty-one affected patients and 20 healthy members of a family with ADPCs (fig. 1) were recruited from the Ophthalmology Service of the General Hospital of Mexico. All patients presented with pulverulent cataracts and underwent surgery at different ages (figs. 1, 2). Genomic DNA was analyzed by WES in the proband, normal daughter, and an affected son, whereas DNA sequencing was performed in all members of the family.

\section{Whole Exome Sequencing}

Two $\mu$ g of genomic DNA were submitted to Axeq Technologies (Rockville, Md., USA) for human exome capture using the SureSelect Human All Exon kit (Agilent Technologies, Santa Clara, Calif., USA). Axeq Technologies performed sample validation, library preparation, exon enrichment, clustering and sequencing using an Illumina HiSeq 2000 Sequencer (Illumina Inc., San Diego, Calif., USA). Approximately 63,000,000 reads of an average size of $107 \mathrm{bp}$ per sample were returned as 2 FASTQ files (one file per orientation). Each pair of FASTQ files was aligned to the human genome (hg19) using the Novoalign mapping tool (http://www.novocraft.com). All parameters were kept at the default settings, as recommended by Novocraft. SAMtools (http://samtools.sourceforge.net/) [Li et al., 2009] was used to sort the SAM files, create BAM files and generate their index files. Picard (http://picard.sourceforge.net/) was used to remove all the PCR duplicates from the BAM files. The Genome Analysis Toolkit (GATK) [McKenna et al., 2010] was used for local
88

Mol Syndromol 2016;7:87-92 DOI: $10.1159 / 000445669$
Messina-Baas et al. 


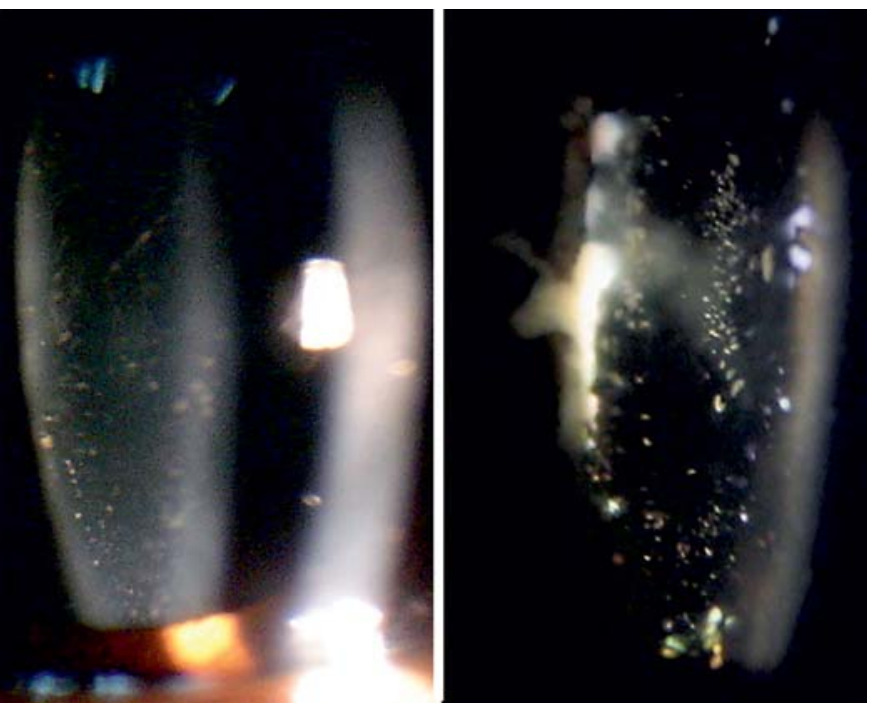

Fig. 2. Sample photographs of the pulverulent/cerulean cataract of the family.

realignments, base quality recalibration and variant calling. Parameters were set as described in GATK's Best Practices v3. GATK generated standard variant call format files (http://www.1000genomes. org/wiki/Analysis/Variant\%20Call\%20Format/vcf-variant-callformat-version-41). These files were annotated using snpEff (snpeff. sourceforge.net) [Cingolani et al., 2012] and ANNOVAR [Wang et al., 2010]. From this point on, we focused our analysis only on the putative coding of nonsynonymous variants. We removed false positive calls by using a post-calling filter that ensures that each variant has a mapping quality $>30$, a base quality $>20$, and a coverage $\geq 10$, so that the variant in reads from both orientations is present. Common variants were removed using allele frequency information from the NHLBI ESP (http://evs.gs.washington.edu/EVS). A common variant was defined as a variant present in the ESP with a minor allele frequency of more than $1 \%$. Every variant was annotated for potential functional effects in the protein using 3 variant effect predictors: SIFT [Kumar et al., 2009], PolyPhen-2 (Prediction of functional effects of human nsSNPs; http://genetics.bwh.harvard.edu/ pph2) [Adzhubei et al., 2010], and MutationTaster (www.mutationtaster.org) [Schwarz et al., 2010].

DdeI Digestion, PCR Amplification, and DNA Sequencing of Exon 6 in the CRYBB2 Gene

$C R Y B B 2$ and $C R Y B B 2 P 1$ genes share a high level of homology. To ensure specific amplification of exon 6 of the $C R Y B B 2$ gene, we developed a test [Gill et al., 2000]. It consists of digesting the genomic DNA before amplification with the restriction enzyme DdeI. DdeI disrupts exon 6 of the CRYBB2 pseudogene and interrupts its amplification. Specifically, we digested $400 \mathrm{ng}$ genomic DNA with 3 units DdeI (New England Biolabs, Beverly, Mass., USA) in a total volume of $10 \mu \mathrm{l}$. After an overnight incubation at $37^{\circ} \mathrm{C}$, we amplified $100 \mathrm{ng}$ of the DdeI-digested genomic DNA using the following conditions: (a) forward primer $5^{\prime}$-CTATCTCTCTCCCCTCGCCTCT-3', (b) reverse primer $3^{\prime}$-CTAGTTGGAGGGGTGGAA-
GGCACC-5', (c) 1.5 mm MgCl2, (d) PCR buffer (GeneAmp II; Perkin-Elmer, Norwalk, Conn., USA), (e) 5\% dimethyl sulfoxide (DMSO), (f) 1 unit DNA polymerase (AmpliTaq, Perkin-Elmer, Norwalk, Conn., USA), (g) $200 \mathrm{~mm}$ dNTPs, and (h) 50 ng exon 6 primer in a final PCR volume of $20 \mu \mathrm{l}$. The hot-start addition of DNA polymerase, after an initial 3 min denaturation $\left(94^{\circ} \mathrm{C}\right)$, was followed by 35 cycles of $30 \mathrm{~s}$ at $94^{\circ} \mathrm{C}, 35 \mathrm{~s}$ at $58^{\circ} \mathrm{C}$, and $40 \mathrm{~s}$ at $72^{\circ} \mathrm{C}$, and it was completed with an 8 -min extension at $72^{\circ} \mathrm{C}$ in a thermocycler (Robocycler Gradient 96; Stratagene; LaJolla, Calif., USA). Amplicons were analyzed with ABI BigDye Terminator Cycle Sequencing kit v3.1 (Applied Biosystems, Foster City, Calif., USA) on an ABI3100 Genetic Analyzer (Applied Biosystems). Detected variants were further sequenced in affected and nonaffected members of the family and in 100 normal controls.

\section{Results}

The initial raw variant call format contained 195,062 putative variants. We isolated 11,502 high-quality, nonsynonymous putative coding variants using our quality filter in conjunction with the annotation tags generated by snpEff [Cingolani et al., 2012]. A similar number of nonsynonymous putative coding variants were isolated by using our quality filters and ANNOVAR [Wang et al., 2010]. The results from WES quickly and efficiently narrowed down the number of variants to 3 possible damaging mutations in genes, GJA3, CRYBA, and CRYBB2. At this point, we validated the variants by Sanger sequencing in all members of the family. After performing the sequencing screening in the 21 affected patients and 20 healthy members of the family, we identified that only the mutation p.Q155* in the gene CRYBB2 cosegregated perfectly with the disorder (fig. 3), unlike in the case of the GJA3 and CRYBA gene variants. To obtain a statistical value for the segregation, we calculated the logarithm of the odds score (LOD). We used a multipoint parametric linkage analysis, Merlin [Abecasis et al., 2002]. We applied an autosomal dominant of inheritance, assuming a disease allele frequency of 0.0001 . We obtained the significant LOD score of 5.5. In terms of significance, an LOD score of 5 means the odds are 100,000:1 that the genes and the disorder are linked. DNA sequencing analysis confirmed the WES finding (fig. 4).

\section{Discussion}

A congenital cataract presents genetic heterogeneity and can be inherited in one of the 3 Mendelian patterns (autosomal dominant, autosomal recessive, and X-linked) with at least 155 reported disease-causing gene mutations 


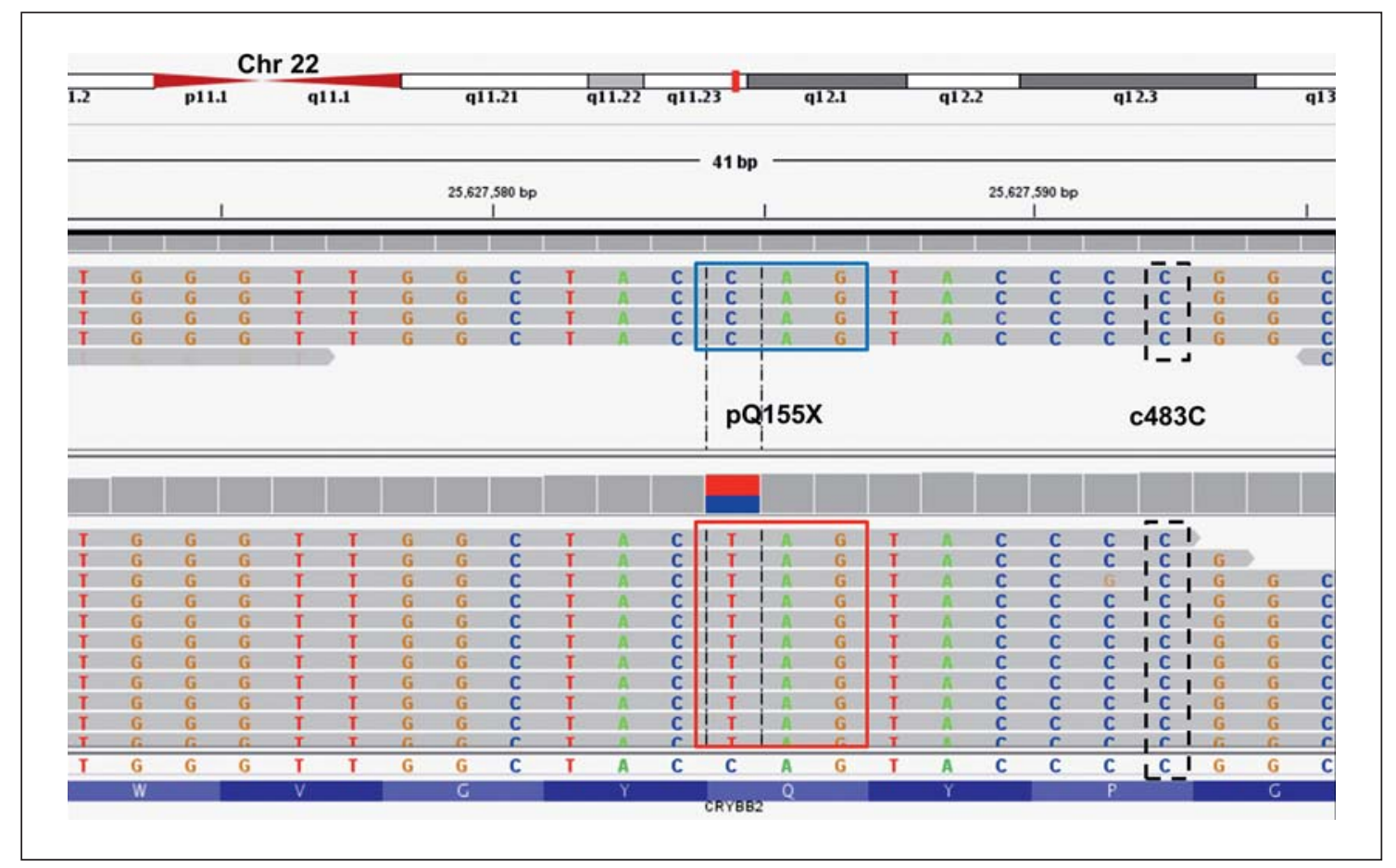

Fig. 3. WES with the heterogeneous change ( $\mathrm{C}$ and $\mathrm{T}$ nucleotides).

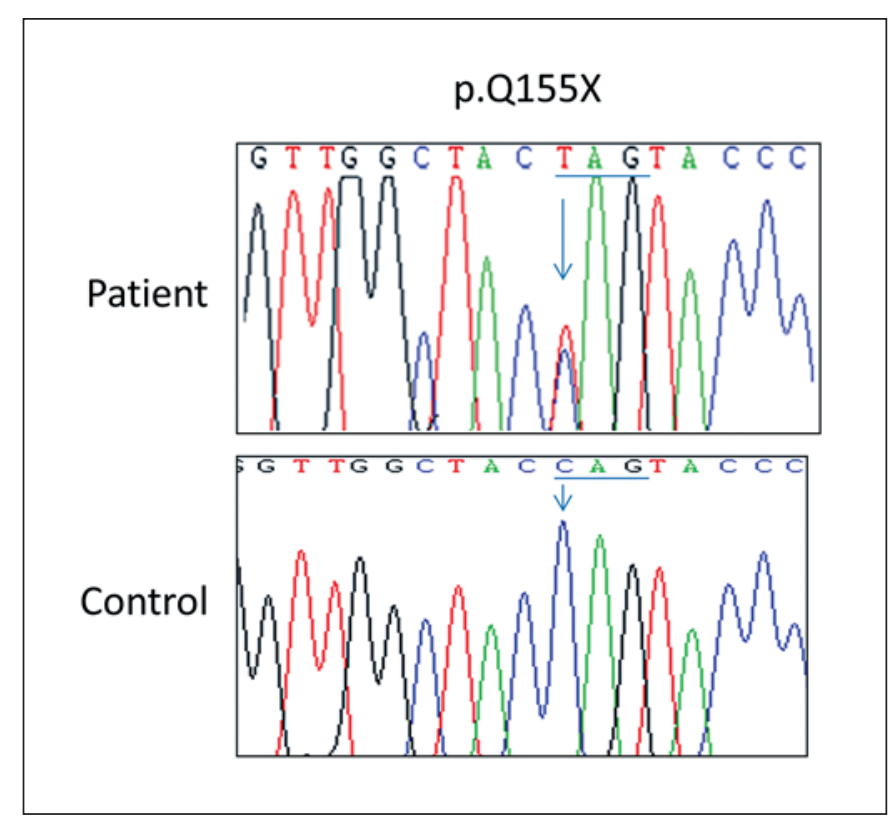

Fig. 4. DNA sequencing analysis confirming the heterozygous change of c. $475 \mathrm{C}>\mathrm{T}$ after digesting with restriction enzyme Ddel. Normal control shows the homozygous state due to elimination of the $C R Y B B 2 P 1$ pseudogene.
[Huang and He, 2010]. For the ADPCs presented by the Mexican family in this study, WES identified the c. $475 \mathrm{C}>\mathrm{T}$ mutation (p.Q155*) in exon 6 in the CRYBB2 gene. In addition, the variants c.895C>A (p.L299M) in GJA3 and c.331A $>\mathrm{C}$ (p.I111L) in CRYGB were also detected. These variants were considered polymorphisms because they were detected in the SNP data base (rs968566 in the GJA3 gene and rs796287 in the CRYGB gene; http://www.ncbi. nlm.nih.gov/snp) and were present in some nonaffected members and absent in some affected members of the family. The nonsense c.475C > T (p.Q155*) mutation has been reported previously in 5 different populations [Litt et al., 1997; Gill et al., 2000; Vanita et al., 2001; Yao et al., 2005; Bateman et al., 2007; Devi et al., 2008; Li et al., 2008], and it predicted a stop codon (p.Q155*) with a loss of 51 amino acids and the 4 Greek key domains in the C-terminal region of the CRYBB2 protein. It is very interesting to note, in spite of the great clinical and genetic heterogeneity in congenital cataracts, that the nonsense mutation p.Q155*, with a chain termination in the human $\beta$-crystallin gene $C R Y B B 2$, seems to be associated exclusively with ADPC (with some clinical variability), independent of the studied population. In addition, it has been demonstrated in a mouse model that the presence of 
Table 1. Mutation p.Q155X in the CRYBB2 gene

\begin{tabular}{|c|c|c|c|c|c|c|c|c|}
\hline hg19 Location & Nuc_Acc & trans_change & Protein & prot_change & rsid & pmid & Country & Reference \\
\hline chr22:25627584C $>\mathrm{T}$ & NM_000496.2 & c. $463 \mathrm{C}>\mathrm{T}$ & NP_000487.1 & p.Q155* & rs74315489 & 9158139 & USA & Litt et al., 1997 \\
\hline chr22:25627584C $>\mathrm{T}$ & NM_000496.2 & c. $463 \mathrm{C}>\mathrm{T}$ & NP_000487.1 & p.Q155* & rs74315489 & 10634616 & Switzerland & Gill et al., 2000 \\
\hline chr22:25627584C $>\mathrm{T}$ & NM_000496.2 & c. $463 \mathrm{C}>\mathrm{T}$ & NP_000487.1 & p.Q155* & rs74315489 & 11424921 & India & Vanita et al., 2001 \\
\hline chr22:25627584C $>\mathrm{T}$ & NM_000496.2 & c. $463 \mathrm{C}>\mathrm{T}$ & NP_000487.1 & p.Q155* & rs74315489 & 17234267 & Chile & Bateman et al., 2011 \\
\hline chr22:25627584C $>\mathrm{T}$ & NM_000496.2 & c. $463 \mathrm{C}>\mathrm{T}$ & NP_000487.1 & p.Q155* & rs74315489 & 18587492 & India & Devi et al., 2008 \\
\hline chr22:25627584C $>\mathrm{T}$ & NM_000496.2 & c. $463 \mathrm{C}>\mathrm{T}$ & NP_000487.1 & p.Q155* & rs74315489 & 18449377 & China & Li et al., 2008 \\
\hline $\operatorname{chr} 22: 25627584 \mathrm{C}>\mathrm{T}$ & NM_000496.2 & c. $463 \mathrm{C}>\mathrm{T}$ & NP_000487.1 & p.Q155* & rs74315489 & 19321936 & China & Wang et al., 2009 \\
\hline chr22:25627584C $>\mathrm{T}$ & NM_000496.2 & c. $463 \mathrm{C}>\mathrm{T}$ & NP_000487.1 & p.Q155* & rs74315489 & 16179907 & China & Yao et al., 2005 \\
\hline
\end{tabular}

hereditary cataracts are due to a mutation consistent in the deletion of 4 amino acids near the C-terminus of $\beta$-B2-crystallin [Chambers and Russell, 1991]. Normal oligomerization of $\beta$-B2-crystallin is not possible due to the lack of these amino acids involved in the stabilization of the native tertiary structure of $\beta$-B2-crystallin of the bovine lens [Bax et al., 1990]. Protein-protein interaction, ordered structure and stability which reduced the cause of changes in biophysical properties were also observed with the p.Q155* mutation [Liu and Liang, 2005].

Previous reports indicated that gene conversion seemed to be the cause of cerulean cataract in 2 families due to a second variant (c.483C $>\mathrm{T}$ ) in exon 6 of the CRYBB2 gene [Bateman et al., 2007]. The rest of the families only describe the point mutation c. $475 \mathrm{C}>\mathrm{T}$, similar to our family. We excluded the possibility of gene conversion because the second variant $\mathrm{c} .483 \mathrm{C}>\mathrm{T}$ was not identified.

The families with cataracts and mutations in the $C R Y B B 2$ gene have clinical variability with different ages of onset. In a previous report, the authors speculated on the cataracts with the c. $475 \mathrm{C}>\mathrm{T}$ mutation and proposed that they may be influenced by the modifiers' cis genetic factors among families and trans genetic and epistatic factors within each family [Vanita et al., 2001]. More studies are necessary to consider the influence or other factors apart from p.Q155* in patients with congenital cataracts. Moreover, due to the genetic heterogeneity and the great number of genes involved in HCCs, WES is an important tool because it provides high coverage to detect variants in genes associated with the disease. A successful model to identify disease-causing genes in HCCs implicates the use of trio sequencing (proband and parents) to be genotyped.

In conclusion, this is the first Mexican family with $\mathrm{AD}$ PCs associated with a p.Q155* mutation in the CRYBB2 gene. Interestingly, this specific mutation in the CRYBB2 gene seems to be associated exclusively with pulverulent/ cerulean cataracts (with some clinical variability) independent of the population's genetic background. In addi-

tion, this study verifies that WES has become a more powerful tool for the detection of genetic origins of cataracts because of its high genetic and clinical heterogeneity.

\section{Acknowledgements}

We thank the family for participating in this study and the DGAPA-PAPIIT UNAM (grant IN204114-2) for financial support.

\section{Statement of Ethics}

Written informed consent was obtained from the participants or their parents prior to the study. The process followed the tenets of the Declaration of Helsinki and followed the Guidance of Sample Collection of Human Genetic Diseases of the Ethics Committee of the General Hospital of Mexico.

\section{Disclosure Statement}

The authors report no conflicts of interest.

References

Mol Syndromol 2016;7:87-92 DOI: $10.1159 / 000445669$
Mutation in CRYBB2 in a Large Mexican Family
-Abecasis GR, Cherny SS, Cookson WO, Cardon LR: Merlin-rapid analysis of dense genetic maps using sparse gene flow trees. Nat Genet 30:97-101 (2002).

-Adzhubei IA, Schmidt S, Peshkin L, Ramensky VE, Gerasimova A, et al: A method and server for predicting damaging missense mutations. Nat Methods 7:248-249 (2010).

Bamshad MJ, Ng SB, Bigham AW, Tabor HK, Emond MJ, et al: Exome sequencing as a tool for Mendelian disease gene discovery. Nat Rev Genet 12:745-755 (2011)

Bateman JB, von-Bischhoffshaunsen FR, Richter L, Flodman P, Burch D, Spence MA: Gene conversion mutation in crystallin, beta-B2 (CRYBB2) in a Chilean family with autosomal dominant cataract. Ophthalmology 114:425432 (2007). 
Bax B, Lapatto R, Nalini V, Driessen H, Lindley $\mathrm{PF}$, et al: X-ray analysis of beta B2-crystallin and evolution of oligomeric lens proteins. Nature 347:776-780 (1990).

-Bermejo E, Martinez-Frías ML: Congenital eye malformations: clinical-epidemiological analysis of 1,124,654 consecutive births in Spain. Am J Med Genet 75:497-504 (1998).

-Bhatti TR, Dott M, Yoon PW, Moore CA, Gambrell D, Rasmussen SA: Descriptive epidemiology of infantile cataracts in metropolitan Atlanta, GA, 1968-1998. Arch Pediatr Adolesc Med 157:341-347 (2003).

-Chambers C, Russell P: Deletion mutation in an eye lens beta-crystallin. An animal model for inherited cataracts. J Biol Chem 266:67426746 (1991).

-Chen W, Chen X, Hu Z, Lin H, Zhou F, et al: A missense mutation in CRYBB2 leads to progressive congenital membranous cataract by impacting the solubility and function of betaB2-crystallin. PLoS One 8:e81290 (2013).

-Cingolani P, Platts A, Wang le L, Coon M, Nguyen $\mathrm{T}$, et al: A program for annotating and predicting the effects of single nucleotide polymorphisms, SnpEff: SNPs in the genome of Drosophila melanogaster strain w1118; iso-2; iso-3. Fly (Austin) 6:80-92 (2012).

-Devi RR, Yao W, Vijayalakshmi P, Sergeev YV, Sundaresan P, Hejtmancik JF: Crystallin gene mutations in Indian families with inherited pediatric cataract. Mol Vis 14:1157-1170 (2008).

Faletra F, d'Adamo AP, Pensiero S, Athanasakis E, Catalano D, et al: A novel CRYBB2 missense mutation causing congenital autosomal dominant cataract in an Italian family. Ophthalmic Genet 34:115-117 (2013).

-Gilbert CE, Canovas R, Hagan M, Rao S, Foster A: Causes of childhood blindness: results from west Africa, south India and Chile. Eye (Lond) 7:184-188 (1993).

- Gill D, Klose R, Munier FL, McFadden M, Priston $\mathrm{M}$, et al: Genetic heterogeneity of the Coppock-like cataract: a mutation in $C R Y B B 2$ on chromosome 22q11.2. Invest Ophthalmol Vis Sci 41:159-165 (2000).

-Gillespie RL, O’Sullivan J, Ashworth J, Bhaskar S, Williams S, et al: Personalized diagnosis and management of congenital cataract by nextgeneration sequencing. Ophthalmology 121: 2124-2137 (2014).

Goh G, Choi M: Application of whole exome sequencing to identify disease-causing variants in inherited human diseases. Genomics Inform 10:214-219 (2012).

-Hansen L, Mikkelsen A, Nürnberg P, Nürnberg G, Anjum I, et al: Comprehensive mutational screening in a cohort of Danish families with hereditary congenital cataract. Invest Ophthalmol Vis Sci 50:3291-3303 (2009).

Hejtmancik JF: Congenital cataracts and their molecular genetics. Semin Cell Dev Biol 19: 134-149 (2008).

-Huang B, He W: Molecular characteristics of inherited congenital cataracts. Eur J Med Genet 53:347-357 (2010).
Inana G, Piatigorsky J, Norman B, Slingsby C, Blundell T: Gene and protein structure of a beta-crystallin polypeptide in murine lens: relationship of exons and structural motifs. Nature 302:310-315 (1983).

Kumar P, Henikoff S, Ng PC: Predicting the effects of coding non-synonymous variants on protein function using the SIFT algorithm. Nat Protoc 4:1073-1081 (2009).

Li FF, Zhu SQ, Wang SZ, Gao C, Huang SZ, et al: Nonsense mutation in the CRYBB2 gene causing autosomal dominant progressive polymorphic congenital coronary cataracts. Mol Vis 14:750-755 (2008).

Li H, Handsaker B, Wysoker A, Fennell T, Ruan $J$, et al: The Sequence Alignment/Map format and SAMtools. Bioinformatics 25:2078-2079 (2009).

- Litt M, Carrero-Valenzuela R, LaMorticella DM, Schultz DW, Mitchell TN, et al: Autosomal dominant cerulean cataract is associated with a chain termination mutation in the human beta-crystallin gene CRYBB2. Hum Mol Genet 6:665-668 (1997).

Liu BF, Liang JJ: Interaction and biophysical properties of human lens Q155* betaB2-crystallin mutant. Mol Vis 11:321-327 (2005).

Lou D, Tong JP, Zhang LY, Chiang SW, Lam DS, et al: A novel mutation in CRYBB2 responsible for inherited coronary cataract. Eye (Lond) 23:1213-1220 (2009).

Lubsen NH, Aarts HJ, Schoenmakers JG: The evolution of lenticular proteins: the beta- and gamma-crystallin super gene family. Prog Biophys Mol Biol 51:47-76 (1988).

Lund AM, Eiberg H, Rosenberg T, Warburg M: Autosomal dominant congenital cataract; linkage relations; clinical and genetic heterogeneity. Clin Genet 41:65-69 (1992).

-McKenna A, Hanna M, Banks E, Sivachenko A, Cibulskis K, et al: The Genome Analysis Toolkit: a MapReduce framework for analyzing next-generation DNA sequencing data. Genome Res 20:1297-1303 (2010).

Mothobi ME, Guo S, Liu Y, Chen Q, Yussuf AS, et al: Mutation analysis of congenital cataract in a Basotho family identified a new missense allele in CRYBB2. Mol Vis 15:1470-1475 (2009).

Muñoz B, West SK: Blindness and visual impairment in the Americas and the Caribbean. $\mathrm{Br} \mathrm{J}$ Ophthalmol 86:498-504 (2002).

Norledge BV, Trinkl S, Jaenicke R, Slingsby C: The X-ray structure of a mutant eye lens beta B2-crystallin with truncated sequence extensions. Protein Sci 6:1612-1620 (1997).

Pauli S, Söker T, Klopp N, Illig T, Engel W, Graw $\mathrm{J}$ : Mutation analysis in a German family identified a new cataract-causing allele in the CRYBB2 gene. Mol Vis 13:962-967 (2007).

Rahi JS, Dezateux C: Congenital and infantile cataract in the United Kingdom: underlying or associated factors. British Congenital Cataract Interest Group. Invest Ophthalmol Vis Sci 41:2108-2114 (2000).
Santhiya ST, Manisastry SM, Rawlley D, Malathi R, Anishetty S, et al: Mutation analysis of congenital cataracts in Indian families: identification of SNPS and a new causative allele in CRYBB2 gene. Invest Ophthalmol Vis Sci 45: 3599-35607 (2004).

- Santhiya ST, Kumar GS, Sudhakar P, Gupta N, Klopp N, et al: Molecular analysis of cataract families in India: new mutations in the CRYBB2 and GJA3 genes and rare polymorphisms. Mol Vis 16:1837-1847 (2010).

Schwarz JM, Rödelsperger C, Schuelke M, Seelow D: MutationTaster evaluates disease-causing potential of sequence alterations. Nat Methods 7:575-576 (2010).

Shafie SM, Barria von-Bischhoffshausen FR, Bateman JB: Autosomal dominant cataract: intrafamilial phenotypic variability, interocular asymmetry, and variable progression in four Chilean families. Am J Ophthalmol 141: 750-752 (2006).

- Shiels A, Hejtmancik JF: Genetic origins of cataract. Arch Ophthalmol 125:165-173 (2007).

-Shiels A, Bennett TM, Hejtmancik JF: Cat-Map: putting cataract on the map. Mol Vis 16: 2007-2015 (2010).

-Stoll C, Alembik Y, Dott B, Roth MP: Epidemiology of congenital eye malformations in 131,760 consecutive births. Ophthalmic Paediatr Genet 13:179-186 (1992).

- Sun W, Xiao X, Li S, Guo X, Zhang Q: Exome sequencing of 18 Chinese families with congenital cataracts: a new sight of the NHS gene. PLoS One 9:e100455 (2014).

-Vanita V, Reis A, Jung M, Singh D, Sperling K, et al: A unique form of autosomal dominant cataract explained by gene conversion between beta-crystallin B2 and its pseudogene. J Med Genet 38:392-396 (2001).

-Wang L, Lin H, Gu J, Su H, Huang S, Qi Y: Autosomal-dominant cerulean cataract in a chinese family associated with gene conversion mutation in beta-B2-crystallin. Ophthalmic Res 41:148-153 (2009).

Wang $\mathrm{K}, \mathrm{Li} \mathrm{M}$, Hakonarson $\mathrm{H}$ : ANNOVAR: functional annotation of genetic variants from high-throughput sequencing data. $\mathrm{Nu}$ cleic Acids Res 38:e164 (2010).

-Wang KJ, Wang BB, Zhang F, Zhao Y, Ma X, Zhu SQ: Novel beta-crystallin gene mutations in Chinese families with nuclear cataracts. Arch Ophthalmol 129:337-343 (2011).

-Weisschuh N, Aisenbrey S, Wissinger B, Riess A: Identification of a novel CRYBB2 missense mutation causing congenital autosomal dominant cataract. Mol Vis 18:174-180 (2012).

- Yao K, Tang X, Shentu X, Wang K, Rao H, Xia K: Progressive polymorphic congenital cataract caused by a $C R Y B B 2$ mutation in a Chinese family. Mol Vis 11:758-763 (2005).

Yao K, Li J, Jin C, Wang W, Zhu Y, et al: Characterization of a novel mutation in the CRYBB2 gene associated with autosomal dominant congenital posterior subcapsular cataract in a Chinese family. Mol Vis 17:144-152 (2011). 